\title{
Plano de manejo comunitário de jacarés na várzea do baixo rio Amazonas, Santarém - PA, Brasil
}

\author{
Rafael Sá Leitão Barboza 1 * \\ George Henrique Rebelo ${ }^{2}$ \\ Roberta Sá Leitão Barboza ${ }^{3}$ \\ Juarez Carlos Brito Pezzuti ${ }^{4}$ \\ ${ }^{1}$ Instituto de Pesquisas Ambientais da Amazônia, Avenida Rui Barbosa, 136 \\ CEP 68005-080, Santarém - PA, Brasil \\ ${ }^{2}$ Instituto Nacional de Pesquisas da Amazônia, Manaus - AM, Brasil \\ ${ }^{3}$ Universidade Federal do Amapá, Macapá - AP, Brasil \\ ${ }^{4}$ Universidade Federal do Pará, Núcleo de Altos Estudos Amazônicos, Belém - PA, Brasil \\ * Autor para correspondência \\ rafabarboza@gmail.com
}

Submetido em 18/09/2012

Aceito para publicação em 13/02/2013

\section{Resumo}

As iniciativas de organização comunitária na várzea do baixo Amazonas apoiadas por acordos de pesca e planos de uso foram elaboradas para o ordenamento do uso dos recursos associados à melhoria da qualidade de vida local. Após diagnóstico participativo envolvendo pesquisadores, extensionistas e comunitários da várzea foram identificadas demandas locais para manejo de fauna na região. Contudo, foram iniciadas atividades com a capacitação de moradores para a realização de contagem de jacarés em 14 comunidades na região do Tapará e Aritapera, com aulas sobre biologia e ecologia de jacarés e manejo de fauna na natureza. Como resultado, foi elaborado, na comunidade Água Preta, um plano de manejo informal de base comunitária para controle e produção de jacarés. O projeto foi elaborado fora de unidade de conservação de uso sustentável, sujeito às normas de outras unidades territoriais de manejo, apoiado em sistemas de co-manejo previamente existentes, porém, com grandes empecilhos para ser implementado.

Palavras-chave: Amazônia; Jacarés; Manejo comunitário; Várzea

\section{Abstract}

Caiman community management plan in lower Amazonian floodplain, Santarém (PA), Brazil. Collective agreements (acordos de pesca and plano de uso) were created by community organization initiatives in the lower Amazon floodplain with the objective to plan the use of natural resources associated with improving quality of life. After a participatory study involving researchers, technicians and floodplain residents, local demands for wildlife management in the region were identified. Accordingly, activities were initiated to train residents to perform caiman surveys in 14 communities around the Tapará and Aritapera regions, incorporating lessons on caiman biology and ecology and wild fauna management. As a result, the Água Preta community drafted an informal management plan for caiman control and to produce meat and leather. The caiman management effort was developed outside sustainable-use protected areas, where it is subject to other territorial management rules and supported by pre-existing co-management systems, but faces many difficulties to be implemented.

Key words: Amazonia; Caiman; Community management; Floodplain 


\section{Introdução}

Populações humanas da bacia amazônica (indígenas, caboclas ribeirinhas, quilombolas, colonos, castanheiros e seringueiros) utilizam uma grande diversidade de recursos naturais para subsistência e através de sistemas de manejo podem contribuir para implementação e fortalecimento de políticas públicas voltadas ao uso sustentável de animais silvestres (BRONDÍZIO, 1999; McGRATH et al., 2008). A participação de entidades que não atuam diretamente na gestão ou uso dos recursos, principalmente as entidades governamentais, formalizam o manejo, onde o governo e os comunitários dividem responsabilidades pelo recurso (SEN; NIELSEN, 1996).

A Agenda 21 brasileira indica que a definição das responsabilidades, a respeito do acesso e uso da fauna selvagem de forma racional, está relacionada ao fortalecimento de mecanismos de controle e monitoramento de produtos comercializados legalmente e à valorização das ações de governos e sociedade (MMA, 2004).

No Brasil, o manejo da fauna tem organização governamental própria apenas para peixes e invertebrados aquáticos, para os quais há o recém-criado Ministério da Pesca e Aquicultura. Experiências de manejo dos recursos pesqueiros na várzea amazônica antecedem estes avanços recentes. As reservas de lago, os acordos de pesca (McGRATH et al., 1993), as Reservas de Desenvolvimento Sustentável (RDS) e Reservas Extrativistas (RESEX) introduziram novas estratégias de intervenção baseadas no trabalho participativo, integrando organizações comunitárias existentes ou promovendo organizações de base com finalidades específicas (associações comunitárias, grupos de manejo, centros comunitários de pesca). Pesquisas participativas geraram conhecimentos de rápida aplicação. As experiências na RDS Mamirauá, no Amazonas, e as regiões dos acordos de pesca da Ilha de São Miguel e da região de Tapará, no Pará, foram pioneiras no manejo pesqueiro há duas décadas (CASTRO, 2000).

Estratégias de manejo comunitário bem sucedidas levaram ao reconhecimento formal e normatização dos acordos de pesca pelo estado. Projetos de manejo comunitário de recursos pesqueiros são ferramentas para consolidar acordos de pesca existentes e estratégias para a co-gestão dos recursos pesqueiros. As principais iniciativas comunitárias de manejo, no baixo Amazonas, incluem o manejo de pirarucu, a proteção das praias de quelônios, as regras para o uso de pastagens comunitárias e a recuperação de habitats florestais e pastagens naturais (McGRATH et al., 2008).

No Brasil o manejo extensivo de fauna silvestre, ao contrário da pesca, recebe pouco incentivo. $\mathrm{O}$ recente manejo de jacarés na RDS Mamirauá (AM) constitui uma exceção, porém ainda há grandes obstáculos a serem vencidos. Fora desta exceção a caça ainda é caso de polícia e a criação em cativeiro é a única saída legal para comercializar qualquer produto da fauna (exceto peixes e crustáceos, mas mesmo para estes há uma tendência ao crescimento da aquicultura). Entretanto, os programas de manejo de jacarés na Amazônia nos estimularam a propor a formulação de um plano de manejo comunitário, cientes de que seria a primeira proposta fora de unidade de conservação de uso sustentável, porém sujeita a normas de outras unidades territoriais de manejo, capazes de contemplar sustentabilidade econômica, social e ambiental.

Na várzea do oeste do Pará, em Santarém, foi financiado um programa de manejo de fauna aquática pelo Ministério da Ciência e Tecnologia (MCT), Conselho Nacional do Desenvolvimento Científico e Tecnológico (CNPq) e Programa Piloto para a Proteção das Florestas Tropicais do Brasil - PPG7, com a participação de pesquisadores do Núcleo de Altos Estudos Amazônicos (NAEA) da Universidade Federal do Pará, do Instituto de Pesquisas Ambientais da Amazônia (IPAM), da Universidade Federal do Amapá (UNIFAP) e Instituto Nacional de Pesquisas da Amazônia (INPA), com a intenção de desenvolver políticas básicas e elementos institucionais para uma abordagem de manejo da várzea com base em ecossistemas (McGRATH et al., 2007). $\mathrm{O}$ projeto, intitulado "Manejo Integrado de Fauna Aquática na Várzea: pirarucu, quelônios e jacarés" (Processo CNPq no 557114/2005-5), teve como um dos componentes construir um plano de manejo comunitário de jacarés na várzea do baixo Amazonas, região do Aritapera e Tapará, com base em pesquisa participante para atender a demanda local. Outro componente foi a articulação política com entidades locais e instituições governamentais e não governamentais. 
Esta iniciativa inovadora ainda recebeu apoio do Projeto Estruturante do Sistema Estadual de Ciência, Tecnologia e Inovação - PIT Pará, que teve como prioridade apoiar iniciativas para formar cadeias produtivas e fortalecer Arranjos Produtivos Locais APLs a partir das matérias-primas produzidas localmente, agregando valor a insumos para serem comercializados no próprio estado, gerando desenvolvimento. No Pará há 26 regiões geoeconômicas com potencial para sediar pólos de inovação tecnológica e segundo o zoneamento ecológico-econômico, inclui no baixo Amazonas, os Municípios de Santarém, Oriximiná e Monte Alegre, onde foi estruturado o APL de pesca e seu Comitê.

Alicerçado nas experiências dos projetos citados acima, este artigo apresenta um sumário sobre como, a partir do diagnóstico participativo envolvendo pesquisadores, extensionistas e comunitários da várzea de Santarém, foi identificada a demanda e depois elaborado um plano de manejo comunitário informal de jacarés na comunidade Água Preta. Os objetivos da pesquisa desenvolvida incluíram: 1) implementar soluções criativas que pudessem pensar em um programa de manejo de jacarés capaz de contribuir com o uso múltiplo dos recursos na várzea, com captura para controle populacional, produção comercial de carne, pele e outros subprodutos (crânio, ossos, dentes e óleo); 2) elaborar uma proposta de manejo de forma participativa, apoiada pela comunidade e especialistas para ser formalizada junto ao IBAMA; e 3) formar equipes de contadores comunitários de jacarés capazes de fazer avaliação populacional e que pudessem se tornar agentes multiplicadores do programa de manejo em outras comunidades e outros PAEs.

\section{Material e Métodos}

\section{Área de estudo}

As várzeas são consideradas "áreas periodicamente inundadas pelo transbordamento lateral de rios ou lagos e/ou pela precipitação direta ou por águas subterrâneas" (JUNK et al., 1989, p. 112). As inundações periódicas, denominadas pulsos de inundação, e alterações no relevo devido à constante deposição de sedimentos carreados pelos rios de água branca (PADOCH et al.,
1999) caracterizam a várzea amazônica como ambiente altamente dinâmico. As várzeas amazônicas são áreas ricas em nutrientes, com grande produtividade natural devido ao aporte anual de sedimentos e alta biomassa (ictiofauna e plantas aquáticas), porém com baixa diversidade de espécies comparada a áreas de terra firme (GOULDING et al., 1996). Tal fato é explicado em função das mudanças que ocorrem nos períodos da subida e descida da água, selecionando adaptações específicas dos seres vivos habitantes desse ecossistema.

A várzea amazônica é considerada uma região de grande importância para as populações humanas, fonte de produtos extrativistas no presente e em tempos remotos. Meggers (1984) indica que os assentamentos indígenas em áreas de várzea eram muito maiores e permanentes em relação à terra firme. A região apresentou ainda um importante papel na economia extrativista da Amazônia, com plantio de cacau, pesca de pirarucu, coleta de "drogasdo-sertão", exploração de peixe-boi, quelônios, jacarés e plantio de juta (VERÍSSIMO, 1985). A dinâmica natural dos sedimentos carreando terras das áreas habitadas (terras caídas) e a deposição de sedimentos (terras crescidas) impõe a constante mudança de moradia dos ribeirinhos (GOULDING et al., 1996; PADOCH et al., 1999).

Considerando as comunidades de várzea da região de Santarém no baixo Amazonas (Figura 1) temos um destacado nível de organização, expresso pelas ações de manejo de recursos pesqueiros ou acordos de pesca locais (McGRATH et al., 1993; CÂMARA; McGRATH, 1995; CRAMPTON et al., 2004). Os acordos foram construídos a partir da década de 1970, como forma de administrar os conflitos entre pescadores comerciais e pescadores locais sobre o acesso aos lagos de pesca (McGRATH et al., 2002). Em resposta, foi gerado o modelo de reservas de lago "baseado no manejo integrado de atividades econômicas com ênfase no gerenciamento comunitário dos recursos" (CÂMARA; McGRATH, 1995). Nas reservas de lago a preservação vai além das espécies-alvo, fornecendo alguma estrutura para incorporar outras espécies no manejo (McGRATH et al., 1993). As comunidades locais modificam seus acordos de pesca a partir das experiências vividas e monitoradas, inovações e regras são partilhadas pelas comunidades, e há intensa troca de conhecimentos e informações de toda natureza. 
FIGURA 1: Localização da Várzea do baixo Amazonas, e comunidade Água Preta.

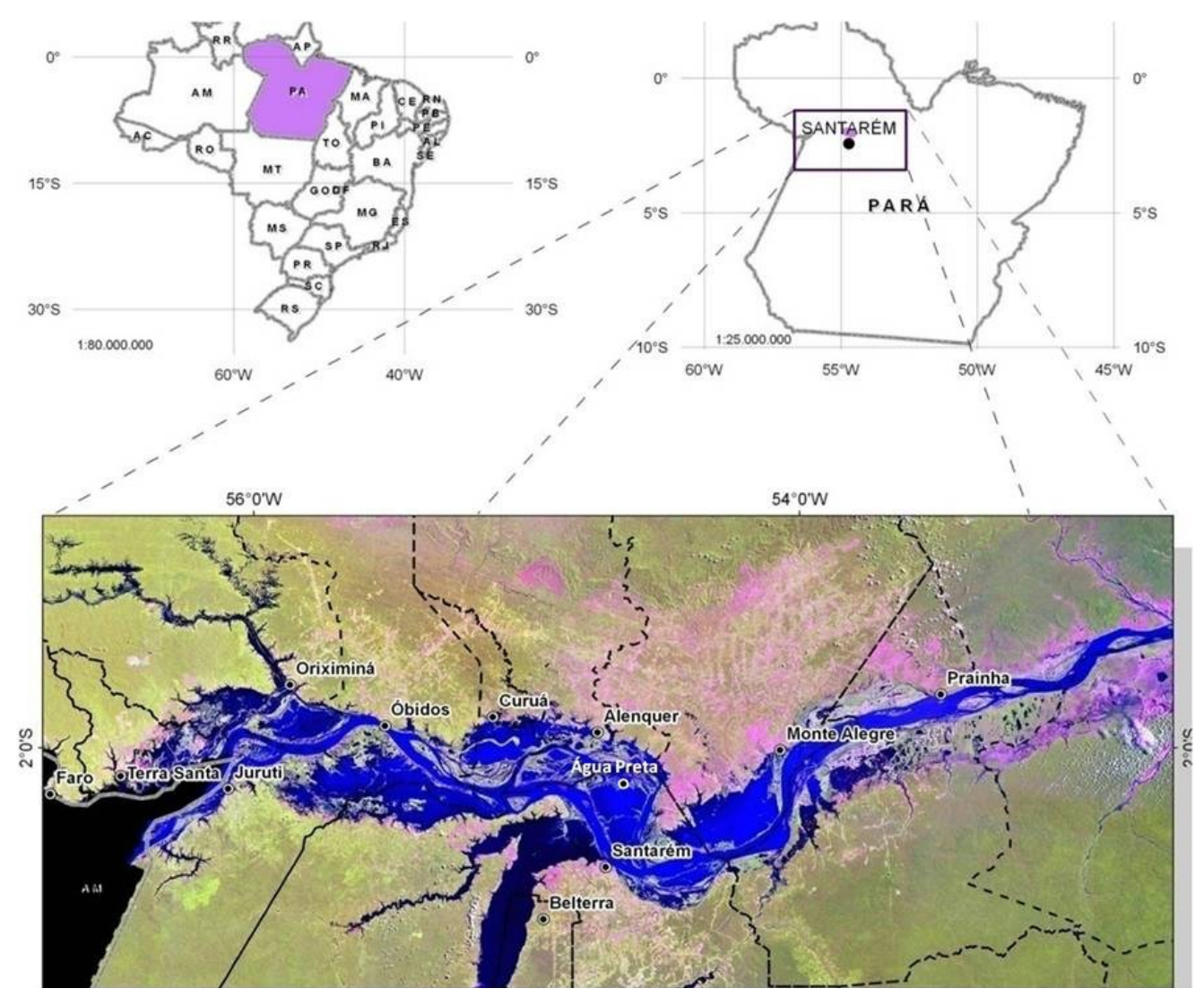

\section{Procedimentos}

Em abril e maio de 2006 pesquisadores do projeto $\mathrm{CNPq}$ "Manejo Integrado de Fauna Aquática na Várzea: pirarucu, quelônios e jacarés" fizeram uma viagem inicial para apresentar a proposta de um estudo sobre manejo de jacaré, quelônios e pirarucus em 14 comunidades das regiões do Tapará e Aritapera explicando os objetivos, as metodologias e a meta de embasar o manejo de vertebrados aquáticos na várzea. Inspirados na experiência local do manejo do pirarucu por várias comunidades, foi proposta a abordagem comunitária e participante. O cenário sugerido incluía as demandas de cada comunidade, o respeito aos acordos de pesca locais, e o estabelecimento de modos de receber contribuições comunitárias para a pesquisa. As comunidades foram indicadas e apresentadas pela equipe de técnicos e pesquisadores do IPAM, com vasta experiência no sistema de co-manejo na várzea de Santarém-PA.
Com a aplicação de ferramentas do Diagnóstico Rural Participativo (DRP) (POFFENBERGER et al., 1992) foi utilizada a metodologia de mapeamento participativo para obter informações sobre os locais de ocorrência da fauna aquática, abrangendo áreas de desova, áreas de forrageio e áreas de pesca. Esta metodologia objetiva a elaboração de mapas temáticos baseados no conhecimento dos comunitários (GASKELL, 2002).

Foram realizados treinamentos e capacitações de comunitários para fazer levantamento do estoque de jacarés contendo noções da biologia, ecologia e manejo de jacarés.

Participaram das oficinas sobre manejo de jacarés, ribeirinhos de 14 comunidades, representantes da Colônia de Pesca Z-20 de Santarém/PA, da Associação de Pescadores e Piscicultores de Pirarucu de Santarém - APPPMS, do Programa de Manejo de Jacarés da Secretaria de Produção Rural do Estado do 
Amazonas (SEPROR-AM) e da Secretaria Estadual de Pesca e Aquicultura do Estado do Pará - SEPAq/ PA, pesquisadores do Instituto de Pesquisa Ambiental da Amazônia - IPAM, do Núcleo de Altos Estudos Amazônicos - NAEA da Universidade Federal do Para - UFPA, do Instituto Nacional de Pesquisa da Amazônia - INPA, da Universidade Federal do Amapá - UNIFAP, e do Museu Paraense Emilio Goeldi - MPEG.

\section{Resultados e Discussão}

\section{A exploração de jacarés}

Os jacarés que existem na várzea da região de Santarém são compostos por três espécies da família Alligatoridae: Caiman crocodilus (tinga), Melanosuchus niger (açu) e Paleosuchus palpebrosus (tiri-tiri ou paguá) (DA SILVEIRA; THORBJARNARSON, 1999; Dados não publicados).

Seguindo uma vertente ecológica, o jacaré é visto com "maus olhos" pelos comunitários, possivelmente, por ser um grande predador topo de cadeia assim como o homem, competindo no mesmo nicho, "lutando" pelo mesmo tipo alimentar e pelo domínio territorial, e ainda, provocando prejuízos mútuos. Jacarés, como os humanos, levam vida de pescadores dos rios tropicais, sendo, portanto competidores diretos pelo recurso e vistos como um tipo de rival pelo peixe desde que os seres humanos chegaram por aqui há dez mil anos. Mas, por cerca de cem milhões de anos o modelo de adaptação "crocodiliano" permaneceu inalterado como o pescador perfeito dos rios tropicais, com base no baixo consumo energético, grande tamanho corporal e muita força (COLINVAUX, 1993). Seres humanos, ao contrário dos jacarés, não são exclusivamente pescadores, conciliando a pesca na várzea com agricultura de pequena escala e coleta de frutos, cocos e castanhas quando da chegada dos europeus, ou antes, (MEGGERS, 1984), e com agricultura familiar, criação de pequenos animais e de gado mais recentemente (McGRATH et al., 2007). Jacarés hoje trazem prejuízos às pescarias, mas já foram produtos importantes. O comércio de peles de jacaré foi a principal causa histórica do declínio dos crocodilianos no Brasil, mas a caça comercial pela pele diminuiu bastante após a lei de proteção à fauna (MAGNUSSON et al., 1997). A partir dos anos 1990 a produção de peles de jacaré (Caiman yacare - jacaré do Pantanal) em fazendas no Pantanal passou a ter legislação específica. Mesmo a espécie C. latirostris (jacaré do papo amarelo), sem legislação exclusiva, é manejada em vários municípios dos estados de RS, SC, SP, ES, MG e AL no sistema tipo farming (Figura 2) (IBAMA, 2012).

FIGURA 2: Imagem representando a ocorrência e intenção dos tipos de manejo de jacarés no Brasil com as respectivas espécies alvo. O círculo vermelho representa a região da várzea de Santarém-PA.

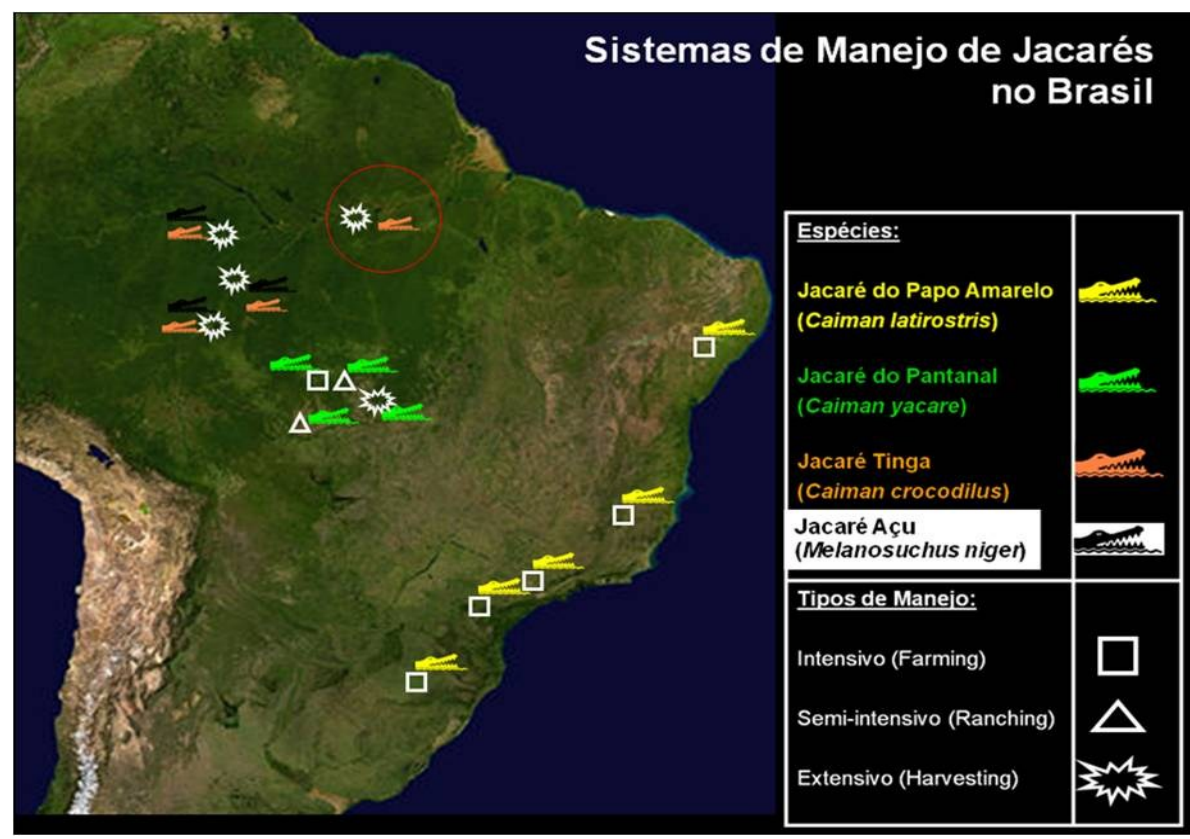


No Brasil, as experiências de manejo com crocodilianos apresentam-se bastante fortalecidas e com histórico de produção reconhecidos, porém, apenas para as espécies $C$. crocodilus (jacaré tinga), $C$. latirostris (jacaré do papo amarelo) e $C$. yacare (jacaré do Pantanal) nas áreas acima indicadas, e ainda, para sistemas de manejo com confinamento, do tipo intensivo (farming) e semi-intensivo (ranching). Na Amazônia brasileira, as atuais experiências de manejo de jacarés, ainda incipientes, são do tipo extensivo (harvesting) para as espécies $C$. crocodilus e M. niger. Os manejos extensivos de jacarés na Amazônia, ainda de maneira experimental, com algumas tentativas comerciais, estão situados nas Unidades de Conservação RDS Mamirauá (AM), RESEX Piagaçu-Purus (AM) e RESEX Lago do Cuniã (RO) (Figura 2) (IBAMA, 2012; IDSM, 2012).

Os tipos de manejo farming, ranching e harvesting apresentam algumas diferenças que podem inviabilizar a implementação do sistema escolhido. As diferenças estão basicamente nos custos, produtividade e abundância natural. O manejo tipo farming é de ciclo fechado, onde toda etapa do ciclo de vida da espécie ocorre em confinamento, elevando os custos, mas a produtividade responde a essa elevação. $\mathrm{O}$ manejo tipo harvesting, denominado caça seletiva, apresenta baixos custos de produção, porém a produtividade é dependente de cotas, mediante a situação natural da espécie, podendo ser muito proveitoso para áreas com alto potencial natural. O tipo de manejo ranching é intermediário entre o farming e harvesting, prevendo a coleta de ovos na natureza, engorda rápida em cativeiro e abate. $\mathrm{O}$ sistema ranching não é um criadouro em ciclo fechado e depende das fêmeas selvagens para produzirem os ovos, assim contorna a lei que considera crime todo abate de animais que não seja para pesquisa científica ou de animais nascidos em cativeiro (CAMPOS et al., 2005). Naturalmente, excetua-se nesse caso a pesca, pela concepção da fauna utilizada pelo Brasil, que determina os animais proibidos de capturar na natureza para comer, vender ou por esporte (fauna silvestre) e os animais para os quais isto é permitido (peixes, moluscos e crustáceos).

As espécies jacaré açu e jacaré tinga estão listados no Apêndice II do CITES (Convenção sobre o Comércio Internacional de Espécies da Flora e da Fauna Selvagens em Perigo de Extinção) com o comércio internacional dos produtos das populações no Brasil permitido sob determinadas condições. Essas condições são hoje produtos de animais criados ou engordados em cativeiro (não há criadouros de jacarés na Amazônia brasileira) ou procedentes dos programas de "manejo de jacarés" na Amazônia - baseados na interpretação de um artigo da lei n. 9985/2000 que institui o SNUC (Sistema Nacional de Unidades de Conservação) e preconiza o manejo de fauna em UC de uso sustentável.

$\mathrm{Na}$ área do presente artigo os primeiros relatos das comunidades da várzea do baixo Amazonas sobre os conflitos entre jacarés e seres humanos indicavam uma demanda pelo controle populacional. Mais do que produção, os pescadores queriam reduzir o prejuízo que o jacaré causava à pesca. Depois, como veremos, o projeto tomou outro rumo.

\section{Construção de um plano de manejo voltado para a exploração sustentável de jacarés no baixo Amazonas}

A aplicação do DRP nas viagens iniciais à campo resultou no mapeamento das áreas de ocorrência, desova e pescaria de quelônios aquáticos podocnemidideos (tartaruga $-P$. expansa; tracajá $-P$. unifilis; e pitiú - P. sextuberculata), de jacarés aligatorideos (Açu Melanosuchus niger; tinga-Caiman crocodilus; e tiritiri - Paleosuchus palpebrosus) e do pirarucu (Arapaima sp.) integrando mapas de todas as comunidades.

Em todas as oficinas de DRP realizadas foi constatada demanda para o manejo de jacarés. A contraresposta do projeto foi planejar e realizar sete oficinas para formular um plano piloto de manejo informal de jacarés nas comunidades. Foi preciso, entretanto, capacitar contadores comunitários para fazer o levantamento das populações/estoques de jacarés e discutir uma agenda de monitoramento comunitário. As duas primeiras oficinas tiveram maior ênfase na capacitação, apresentando noções sobre biologia e ecologia de jacarés, manejo de fauna na natureza, e atividades práticas para capacitação dos comunitários para aplicar a metodologia básica para contagem de jacarés, bem como registrá-los (Figura 3). Os pesquisadores ensinaram as contagens noturnas de 
FIGURA 3: a) Jacarés no lago Mauari de Baixo, comunidade Água Preta (novembro de 2007); b) Oficina de manejo comunitário na comunidade Centro do Aritapera (fevereiro de 2007); c) Comunitário manipulando jacaré; d) Mapeamento participativo.

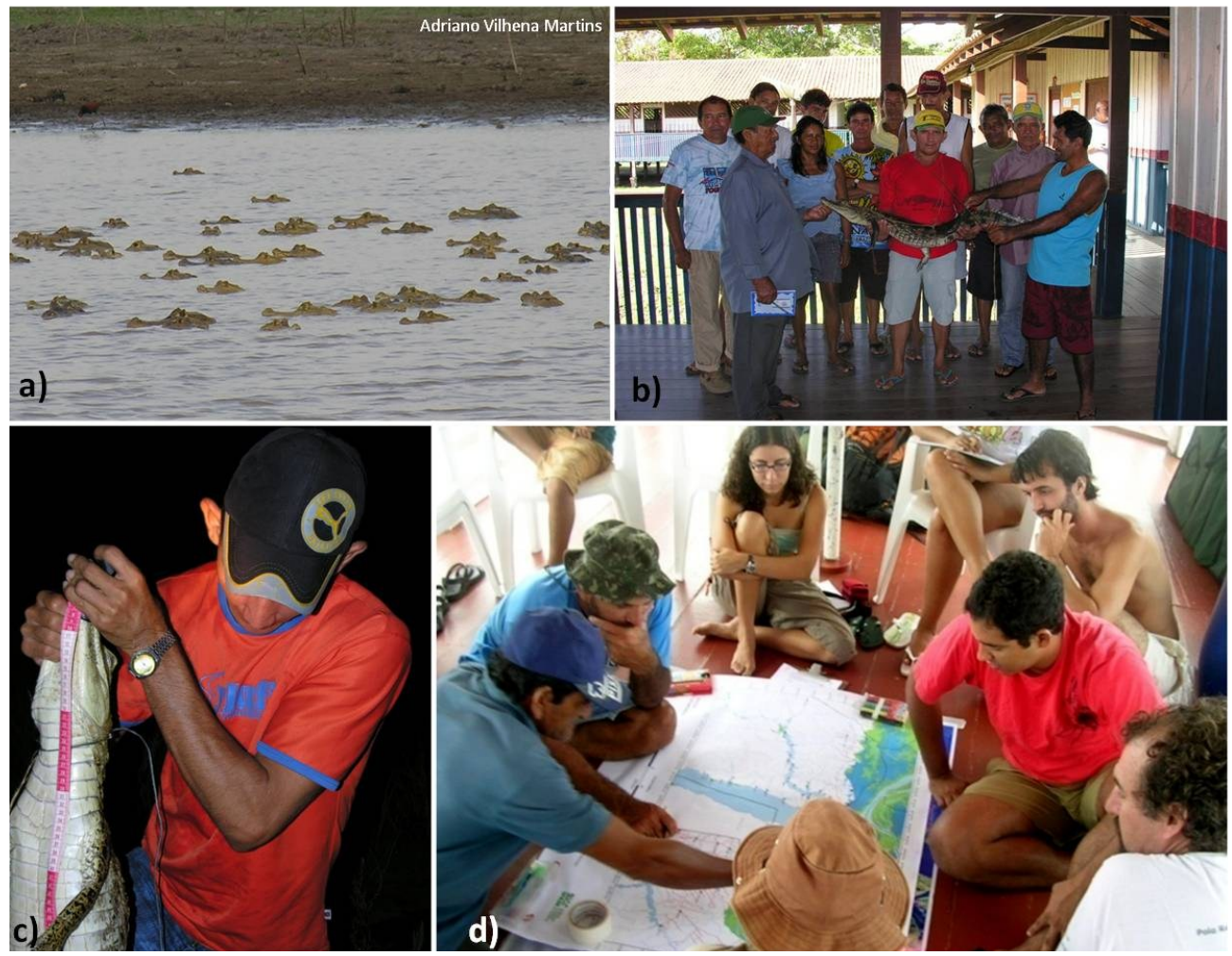

jacarés realizadas seguindo protocolos com embarcações rápidas (embarcação de alumínio com motor de popa a partir de $15 \mathrm{hp}$ ) e alto consumo de combustível. A metodologia das contagens foi adaptada para ser realizada pelos comunitários: com contagens silenciosas a remo, utilizando econômicos e lentos motores tipo rabeta (3,5hp, $4,5 \mathrm{hp} \mathrm{e} 5,5 \mathrm{hp}$ ) para o deslocamento entre as comunidades e os locais de contagem, também consideradas apropriadas para o contexto local. Essa interação resultou na elaboração de um protocolo mínimo de contagens de jacarés pactuado entre pesquisadores e comunitários, que foi utilizado durante todo o estudo (incluindo identificação das espécies, tamanho estimado, biometria de animais capturados, identificação de sexo, e marcação, identificação e contagem de ninhadas, ambientes e microambientes onde os indivíduos estavam presentes e vegetação predominante). As estimativas utilizadas para o cálculo de densidade e do índice de perturbação foram todas produto do trabalho voluntário comunitário.

As equipes comunitárias se organizaram por função elencadas por eles mesmos, sendo as principais: 1) piloto (conduz e direciona a embarcação); 2) focador/ laçador (direciona o feixe de luz, localiza, conta, estima o tamanho e laça ou captura os animais - uma pessoa com apoio de outra durante a captura); e 3) escrivão (anotador dos dados coletados em planilhas de campo uma pessoa); todos se reconhecendo como conferidores de jacarés. Para verificar a congruência entre as contagens feitas pelos conferidores e contagens feitas por pesquisadores, estes fizeram contagens de validação, repetindo os procedimentos com poucos dias de intervalo em $10 \%$ das contagens escolhidas por sorteio.

As contagens comunitárias e de validação feitas onde hoje são os PAEs Tapará e Aritapera, somadas, totalizaram 74 contagens desde 2006 até 2009. Com o tempo, o número de comunidades e participantes nas oficinas diminuiu e o programa só não foi encerrado por que os comunitários da comunidade Água Preta (PAE Aritapera) foram notavelmente obstinados (Figura 4). O aumento do desinteresse no manejo ou a redução na participação das comunidades sugere alguma frustração de expectativas. Informalmente 
foram alegados os seguintes motivos (sem ordem de importância): desinteresse na participação voluntária (sem remuneração), conflitos internos (comunitários), comunicação deficiente e ausências prolongadas dos pesquisadores, indefinições estruturais, sobreposição com atividades cotidianas, sobrecarga de trabalho para lideranças, ausência de perspectiva de ganhos em curto prazo, trabalho arriscado, falta de apoio para contar jacaré, falta de clareza dos objetivos do programa, obstáculos burocráticos e legais para o manejo, ceticismo sobre os resultados do programa e interferências do jogo político-partidário no diálogo (necessário) entre comunidades, academia e outras instituições.

Em 2008 foram feitos registros detalhados de vinte interações entre jacarés e pescadores na área de vida da comunidade Água Preta. Sete jacarés foram mortos por pescadores (quatro tingas e três açus) e nenhum "produto" aproveitado. Outros dois tingas foram mortos por pescadores de fora e também nenhum produto foi retirado (nem mesmo carne, que sabidamente tem algum valor no mercado informal regional). Essas mortes devem estar relacionadas de algum modo com os ataques de jacarés (e forrageio) sobre animais domésticos (principalmente pato), a destruição de arreios de pesca e os confrontos diretos entre jacarés e seres humanos (duas demonstrações de ferocidade e um acidente não fatal). Este quadro das interações, detalhado na Água Preta (Tabela 1), se repete em outras comunidades, representando interações comuns entre homem e jacaré ao longo da várzea do baixo Amazonas.

A captura seletiva de alguns animais que provocam prejuízos ou podem provocar risco de morte constitui um programa de controle populacional de jacarés, que precisa se ajustar a dois marcos legais. O primeiro é a Lei de Proteção à Fauna (Lei no 5197/67), que no seu Art. 1을 estabelece que: "os animais de quaisquer espécies, em qualquer fase do seu desenvolvimento e que vivem naturalmente fora do cativeiro, constituindo a fauna silvestre, bem como seus ninhos, abrigos e criadouros naturais são propriedades do Estado, sendo proibida a sua utilização, perseguição, destruição, caça ou apanha". Mas no parágrafo 1ำ adverte que "se peculiaridades regionais comportarem o exercício da caça, a permissão será estabelecida em ato regulamentador do Poder Público Federal". O Art. 2º proíbe o exercício da caça profissional e o Art. $3^{\circ}$ proíbe o comércio de espécimes da fauna silvestre e de produtos e objetos que impliquem na sua caça, perseguição, destruição ou apanha, excetuando apenas espécimes provenientes de criadouros legalizados; ovos, larvas e filhotes que se destinem aos estabelecimentos referidos; e a "destruição de animais silvestres considerados nocivos à agricultura ou à saúde pública" (mediante licença da autoridade competente) (Grifos nossos). O outro marco legal é Lei de Crimes Ambientais (Lei no 9.605/98), que no seu Artigo 37 não considera crime o abate de um animal

FIGURA 4: Variação no número de participantes e no número de comunidades nas oficinas sobre manejo de jacarés na várzea de Santarém, entre julho de 2006 e maio de 2009.

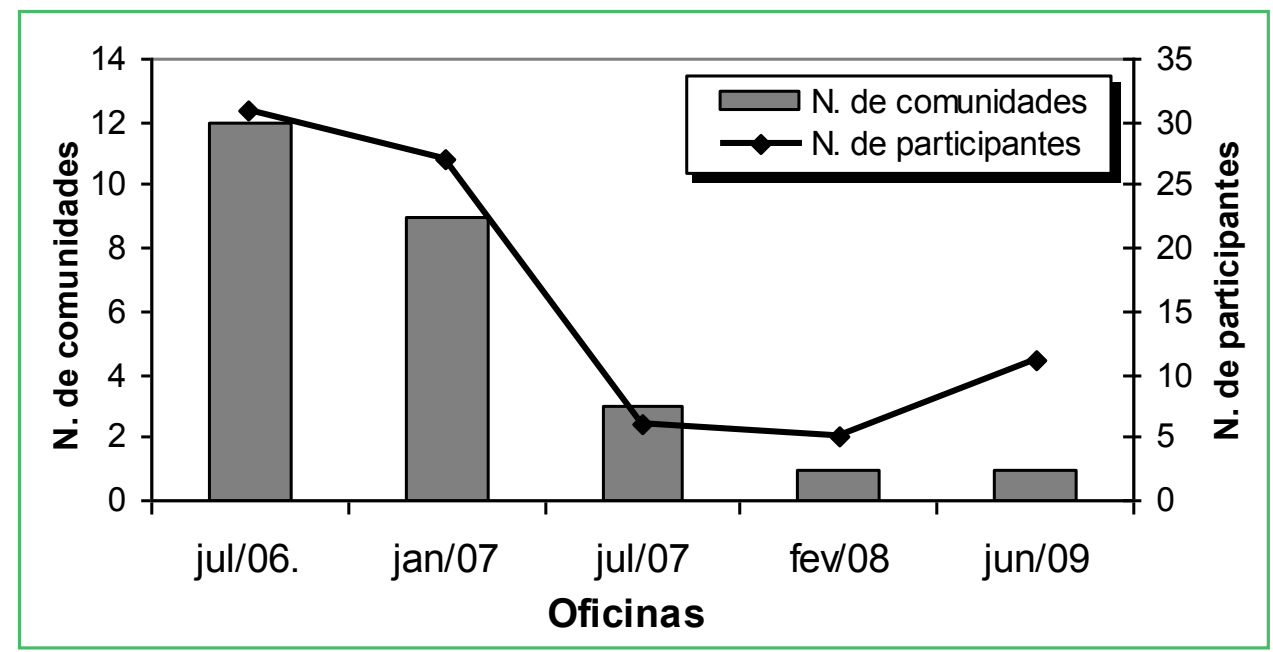


TABELA 1: Interações envolvendo jacarés e moradores da comunidade Água Preta (PAE Aritapera, Santarém-PA) ocorridas durante o período compreendido entre o início de 2007 e fevereiro de 2008.

\begin{tabular}{|c|c|c|c|c|}
\hline $\begin{array}{r}\text { Por Local } \\
\end{array}$ & \multicolumn{4}{|c|}{ Número de interações } \\
\hline Igarapé do Lago & \multicolumn{4}{|c|}{2} \\
\hline Lago Agua Preta & \multicolumn{4}{|c|}{10} \\
\hline Lago Cuinha & \multicolumn{4}{|c|}{2} \\
\hline Lago Itarim & \multicolumn{4}{|c|}{3} \\
\hline Lago Mauari & \multicolumn{4}{|c|}{3} \\
\hline Total Geral & \multicolumn{4}{|c|}{20} \\
\hline \multirow{2}{*}{ Por Espécie } & \multicolumn{3}{|c|}{ Sexo } & \\
\hline & Fêmea & Macho & Indefinido & Total \\
\hline Açu & 0 & 3 & 4 & 7 \\
\hline Tinga & 1 & 4 & 4 & 9 \\
\hline Não identificado & 0 & 0 & 4 & 4 \\
\hline \multirow{2}{*}{ Tipo de Interação } & \multicolumn{3}{|c|}{ Espécie } & \\
\hline & Açu & Tinga & Indefinida & Total \\
\hline Abate do animal & 3 & 4 & 0 & 7 \\
\hline Acidente com vítima ferida & 0 & 0 & 1 & 1 \\
\hline Animal encontrado morto & 0 & 2 & 0 & 2 \\
\hline Ataque a animal doméstico & 2 & 1 & 1 & 4 \\
\hline Avanço sobre o pescador & 2 & 0 & 0 & 2 \\
\hline Destruição de arreio de pesca & 0 & 1 & 2 & 3 \\
\hline Encontro de ninho & 0 & 1 & 0 & 1 \\
\hline
\end{tabular}

silvestre "I) em estado de necessidade, para saciar a fome do agente ou de sua família; II) para proteger lavouras, pomares e rebanhos da ação predatória ou destruidora de animais, desde que legal e expressamente autorizada pela autoridade competente; e IV) - por ser nocivo o animal, desde que assim caracterizado pelo órgão competente" (Grifos nossos). Portanto existem alguns meios de aprovar um programa de controle populacional (com indicadores da redução de prejuízos à pesca), que possam render alguns produtos comercializáveis. $\mathrm{Na}$ prática a população local dificilmente teria meios de conseguir obter esta licença, daí a necessidade e importância de desenvolver parcerias com instituições públicas e privadas.

Com fins de controle e produção, a seleção de áreas para captura deve ser inspirada no modelo fontedreno de dinâmica populacional, identificando lagos de preservação (1) fonte de reprodução de jacarés abastecendo estes e outros lagos para produção (2), os "drenos" onde serão capturados os animais selecionados. A identificação dos locais de nidificação é necessária para definir áreas de proteção ou áreas fonte (CAMPOS,
2003). Tendo seguido boas práticas de manejo comunitário de fauna (BODMER; PUERTA, 2000; PUERTA et al., 2004) seguimos por etapas por ordem cronológica: 1) avaliamos demandas; 2) definimos um desenho experimental; 3) capacitamos comunitários que; 4) coletaram os dados; 5) avaliamos e analisamos juntos o monitoramento; 6) integramos resultados de todas as comunidades; 7) elaboramos proposta de plano de manejo informal (PMI) como projeto de pesquisa com captura experimental; 8) discutimos com os comunitários propostas e 9) tomamos decisões conjuntas.

Após as etapas descritas acima, foi realizada uma reunião em Santarém com comunitários, pesquisadores e técnicos da SEPAq, ICMBio, IPAM e outras instituições com o intuito de solicitar licença de pesquisa para captura experimental e fornecer novas informações e restrições ao manejo de jacarés. O plano de utilização (PU) do PAE Aritapera, assim como em quinze PAEs de várzea do baixo Amazonas, proíbe manejo de fauna exceto se autorizado por comunitários, conselho, diretoria, IBAMA e outros órgãos. Mesmo que a venda de qualquer artigo de jacaré seja improvável a curto e médio prazo, 
se autorizada a captura experimental podemos completar as seguintes etapas: 10) avaliar rendimento da carcaça, analisar qualidade da carne e aceitação dos produtos (degustação); 11) dar continuidade ao monitoramento das populações sob manejo informal; 12) apresentar proposta de captura para abate para controle e produção; (13) implementar o plano de manejo; 14) publicar os resultados; 15) multiplicar o programa de manejo para outras comunidades na várzea.

O projeto de pesquisa encaminhado por meio do SISBIO/IBAMA planejou para que, em janeiro de 2010, ocorresse o período para captura experimental, para assim, abater 20 jacarés $C$. crocodilus adultos (entre 1,50 $\mathrm{m}$ e 2,00 $\mathrm{m}$ de comprimento total), os quais seriam capturados e transportados até a unidade de processamento flutuante que seria emprestada pela Universidade Federal do Amazonas. Seriam registrados os rendimentos de carne e pele, cujas amostras iam ser submetidas às análises de qualidade e contaminação. Para verificar a aceitação da carne de jacaré um projeto de eventos de divulgação e degustação seria desenvolvido em Santarém e Belém.

Os comunitários da Água Preta estabeleceram prérequisitos para participar do projeto: maior de 18 anos e associado na colônia de pescadores Z-20 do município de Santarém/PA ou da Associação Comunitária Água Preta-ACAP. Decidiram que qualquer descumprimento mal intencionado das decisões tomadas no plano de manejo informal, como destruir ninhos ou matar jovens, filhotes e/ou fêmeas com ninhadas na área da comunidade, implicaria no risco de sofrer sanções, como não participar do trabalho e, portanto, não usufruir dos possíveis ganhos com a venda da carne, pele e outros subprodutos. Caso a venda de qualquer produto fosse autorizada, os comunitários da Água Preta já tinham definido que qualquer membro da comunidade, que tenha concordado com a integração da comunidade no projeto e feito a confirmação no abaixo assinado, poderia participar das capturas, e o lucro seria dividido entre participantes e a associação comunitária. O projeto com essa configuração não foi consolidado, atualmente está em fase de fortalecimento das pesquisas participativas em campo e consequente reformulação.

\section{As perspectivas para o manejo}

A noção de fauna na natureza como um bem intocável da União ou como um produto, aceitável apenas se fruto da criação ou engorda em cativeiro, parece cada vez mais sólida no Brasil. Os ícones dos produtos do extrativismo que mais sofreram exploração com consequente ameaça de extinção foram onças, araras, peixe-boi, tartaruga e jacaré açu, na década de 1960, que justificaram e ainda justificam a adoção de uma lei draconiana que a (quase) tudo proíbe. Apesar da ênfase no controle e fiscalização ter sido a política de fauna predominante em quatro décadas, o mercado consumidor regional nunca deixou de existir, mas mergulhou e se adaptou à informalidade das "encomendas" de mantas salgadas de jacarés (nas maiores cidades) ou na comercialização aberta (no interior), cujo maior exemplo no Pará é a feira livre de Abaetetuba, onde a carne de jacaré está entre as mais vendidas e procuradas por uma clientela de baixo poder aquisitivo. A carne de caça, incluindo jacaré, é bem mais barata que as carnes "nobres" bovina, suína e também do que o pescado, mas não concorre com o frango (BAÍA JÚNIOR, 2006). Ou seja, apesar da carne de jacaré ser um produto desvalorizado na Amazônia, consumido pelas classes mais pobres, é o único produto da espécie com grande mercado atual, mesmo sendo informal, e ainda que o potencial econômico da pele e de outros produtos seja incerto (DA SILVEIRA; THORBJARNARSON, 1999).

NaRDS Mamirauá o manejo busca a sustentabilidade da caça de jacarés onde eles são muito abundantes, com as maiores densidades de jacaré açu da Amazônia, mesmo após 15 anos de captura e comércio ilegal (DA SILVEIRA; THORBJARNARSON, 1999). Com estes números, em 2004 foi autorizada a captura experimental seguida do abate comercial em 2006 e 2008. Devido às dificuldades encontradas desde o processo de abate à comercialização dos produtos foi realizado em 2010 um novo abate experimental. Todavia, mesmo com infraestrutura específica, porém ainda inadequada, e abundância suficiente de jacarés que justifiquem um abate comercial há muitos desafios para alcançar a sustentabilidade e autonomia das comunidades envolvidas. 
$\mathrm{Na}$ várzea do baixo Amazonas a abundância de jacaré açu é inviável para ser utilizada em sistemas de manejo com aproveitamento comercial, diferentemente do jacaré tinga, o qual apresenta-se mais abundante (Dados não publicados). O jacaré açu poderia ser o alvo principal: é a espécie maior, representa uma ameaça real às pessoas, rende mais carne e teve a pele mais valorizada no passado, porém, a abundância é reduzida e não foram encontradas evidências de reprodução desta espécie na área de entorno da comunidade Água Preta (ninhos, ovos, filhotes ou ninhadas). Contudo, se as áreas fonte não forem encontradas, pode não haver controle populacional da espécie manejada. Num sistema de duas espécies propusemos proteger o açu e capturar o tinga (mais abundante), mas esta estratégia conservadora pode ser revista a qualquer momento (manejo adaptativo). Foram identificadas inúmeras áreas de nidificação para os jacarés tinga durante procuras ativa na área entorno dos corpos hídricos da comunidade, entre 2009 e 2011 (dados não publicados).

A percepção que comunitários ao longo da várzea do baixo Amazonas possuem sobre a abundância de jacarés no entorno de suas comunidades é bem discrepante do real encontrado nas avaliações e estimativas populacionais com critérios científicos, podendo esse resultado até torná-los incrédulos sobre a utopia de um manejo visando produção comercial com aproveitamento econômico dos produtos oriundos da grande quantidade de jacarés. É unânime o comentário de que a quantidade de jacarés é altíssima e que há muitos animais de grande porte em volta das comunidades.

Alegar que a redução da quantidade de jacarés irá extinguir as interações negativas com os mesmos e irá aumentar o estoque pesqueiro é uma justificativa que exclui os crocodilianos da interação ecológica. Sabe-se que a ausência de predadores topos de cadeia como felinos, canídeos, grandes peixes carnívoros e mamíferos aquáticos interfere negativamente na dinâmica populacional dos ecossistemas que habitam (ESTES et al., 2011). A captura seletiva de tinga pode contribuir para reduzir as interações negativas, porém dificilmente irá extingui-las ou aumentar o estoque pesqueiro.
Mesmo que a venda dos produtos de animais abatidos para controle populacional seja questionável, o principal ganho alegado pela comunidade seria reduzir as perdas e prejuízos à pesca e à pequena criação, desde que o programa fosse monitorado e planejado para escolher quais indivíduos e ou tamanhos individuais fossem abatidos. Esta poderia ser uma contribuição do manejo de fauna ao uso múltiplo e integrado de recursos da várzea, podendo contribuir com a renovação dos estoques pesqueiros, mitigação do comércio ilícito, valorização da carne de jacaré como fonte proteica e melhoria da qualidade de vida dos comunitários. Poderia contribuir ainda para a organização comunitária, com o desenvolvimento de suas entidades e estimulo à participação. A comunidade já iniciou discussões sobre a possibilidade de incluir as atividades de monitoramento das populações de jacarés em programas de turismo de base comunitária.

Um programa de manejo com enfoque no ecossistema depende da capacidade comunitária de conciliar os interesses coletivos e individuais (MEFFE et al., 2002). A falta de restrição do acesso e uso aos lagos comunitários por quem não é responsável pelo manejo é o maior entrave para o sucesso dessas atividades, pois quem consegue usufruir dos benefícios advindos do esforço de outros (McGRATH et al., 2008) também não tem motivos para obedecer qualquer limite. O livreacesso desafia o princípio básico do manejo de recursos de uso comum: "somente os que trabalham para criar o sistema devem ter uso exclusivo do benefício gerado pelo seu trabalho" (BENATTI et al., 2003, p. 143). No caso dos jacarés, o problema não é o livre-acesso (situação de fato para a fauna), mas a proibição ao livre-comércio (direito dos comunitários se licenciados). Mesmo com a regularização fundiária, licenciamento e implementação dos PAEs na várzea do baixo Amazonas, o plano de manejo informal de jacarés se choca com as diretrizes políticas dos PAEs, os PUs, ao prever (involuntariamente) a comercialização de produtos e não apenas o controle das populações de jacaré açu e tinga e retrata os interesses de apenas uma comunidade (Água Preta), situada em área sob jurisdição de conselho regional com limites definidos e inúmeras restrições ao uso dos lagos. 


\section{Referências}

BAÍA JÚNIOR, P. C. Caracterização do uso comercial e de subsistência da fauna silvestre no município de Abaetetuba, PA. 2006. 128 f. Dissertação (Mestrado em Ciência Animal) Universidade Federal do Pará, Belém. 2006.

BENATTI, J. H.; MCGRATH, D. G.; OLIVEIRA, A. C. M. Políticas públicas e manejo comunitário de recursos naturais na Amazônia. Ambiente \& Sociedade, Campinas, v. 5, n. 2, p. 137-154, 2003.

BODMER, R. E.; PUERTA, P. Community-based co-management of wildlife in the Peruvian Amazon. In: ROBINSON, J. G ; BENNET, E. L. (Ed.). Hunting for sustainability in tropical forests. New York: Columbia University Press, 2000. p. 51-76.

CÂMARA, E. P. L; McGRATH, D. G. A viabilidade da Reserva de lago como unidade de manejo sustentável dos recursos da várzea amazônica. Boletim Museu Paraense Emílio Goeldi, ser. Antropologia, Belém, v. 11, n. 1, p. 109, 1995.

CAMPOS, Z. M. Observações sobre a biologia reprodutiva de três espécies de jacarés na Amazônia Central. Corumbá: Embrapa Pantanal, 2003. 19 p. (Comunicação Técnica)

CAMPOS, Z. M.; MOURÃO, G.; COUTINHO, M. Avaliação de três modelos de manejo para o jacaré do Pantanal. Boletim de Pesquisa e Desenvolvimento. Corumbá: Embrapa Pantanal, 2005. 4 p.

CASTRO, F. Fishing accords: the political ecology of fishing intensification in the Amazon. 2000. 346 f. PhD Dissertation (Doctorate in Philosophy in the School of Public and Environmental Affairs) - Indiana University, Bloomington. 2000.

COLINVAUX, P. Pleistocene biogeography and diversity in tropical forests in South America. In: GOLDBLATT, P. (Ed.). Biological relationships between Africa and South America. New Haven: Yale University Press, 1993. p. 473-499.

CRAMPTON, W. G. R.; VIANA, J. P.; CASTELlO, L.; DAMASCENO, J. M. Fisheries management in the Mamirauá sustainable development reserve. In: SILVIUS, K. M.; BODMER, R. E.; FRAGOSO, J. M. V. (Ed.). People in nature: wildlife conservation in South and Central America. New York: Columbia University Press, 2004. p. 99-122.

Da SILVEIRA, R.; J. B. THORBJARNARSON. Conservation implications of commercial hunting of black and spectacled caiman in the Mamirauá Sustainable Development Reserve, Brazil. Biological Conservation, Boston, v. 88, p. 103-109, 1999.

ESTES, J. A.; TERBORGH, J.; BRASHARES, J. S.; POWER, M. E.; BERGER, J.; BOND, W. J.; CARPENTER, S. R.; ESSINGTON, T. E.; HOLT, R. D.; JACKSON, J. B. C.; MARQUIS, R. J.; OKSANEN, L.; OKSANEN, T.; PAINE, R. T.; PIKITCH, E. K.; RIPPLE, W. J.; SANDIN, S. A.; SCHEFFER, M.; SCHOENER, T. W.; SHURIN, J. B.; SINCLAIR, A. R. E.; SOULÉ, M. E.; VIRTANEN, R.; WARDLE, D. A. Trophic downgrading of Planet Earth. Science, New York, v. 333, p. 301-306, 2011.

GASKELL, G. Entrevistas individuais e grupais. In: BAUER, M. W.; GASKELL, G. (Ed.). Pesquisas qualitativas com texto, imagem e som: um manual prático. Petrópolis: Vozes, 2002. p. 64-89.

GOULDING, M.; SMITH, N. J. H.; HAHAR, D. J. Floods of fortune - ecology and economy along the Amazon. New York: Columbia University Press, 1996. 193 p.

IBAMA. Instituto Brasileiro de Meio Ambiente e Recursos Naturais Renováveis. 2012. Disponível em: <http://www.ibama. gov.br>. Acesso em: 22 jan. 2012.
JUNK, W. J.; BAYLEY, P. B.; SPARKS, R. E. The flood pulse concept in riverfloodplain systems. Canadian Special Publication of Fisheries and Aquatic Sciences, Otawa, v. 106, p. 110-127, 1989. MAGNUSSON, W. E.; LIMA, A. P.; COSTA, V. L.; LIMA, A. C.; ARAÚJO, M. C. Growth during middle age in Schneider's Dwarf caiman, Paleosuchus trigonatus. Herpetological Review, St. Louis, v. 28, n. 4, p. 183. 1997.

IDSM. Instituto de Desenvolvimento Sustentável Mamirauá. 2012. Disponível em: <http://www.mamiraua.gov.br>. Acesso em: 14 maio 2012.

McGRATH, D. G., ALMEIDA, O. T.; MERRY, F. D. The influence of community management agreements on household economic strategies: cattle grazing and fishing agreements on the lower Amazon floodplain. International Journal of the Commons, Bloomington, v. 1, n. 1, p. 67-87. 2007.

McGRATH, D. G.; CARDOSO, A.; ALMEIDA, O. T.; PEZZUTI, J. Constructing a policy and institutional framework for an ecosystem-based approach to managing the lower Amazon floodplain. Environment, Development and Sustainability, London, v. 10, p. 677-695, 2008.

McGRATH, D. G.; CARDOSO, A.; SÁ, P. E. Community fisheries and co-management on the lower Amazon floodplain of Brazil. International symposium of the management of large rivers for fisheries: sustaining livelihoods and biodversity in the new millennium. Cambodia: FAO and Mekong River Commission, 2002. p. 207-222.

McGRATH, D. G.; CASTRO, F.; FUTEMMA, C.; AMARAL, B.; CALÁBRIA, J. Fisheries and the evolution of resource management on the lower Amazon floodplain. Human Ecology, Ithaca, v. 21, p. 167-195, 1993.

MEFFE, G.; NIELSEN, L.; KNIGHT, R.; SCHOENBORN, D. Ecosystem management. Washington: Island Press. 2002. 327 p.

MEGGERS, B. J. The indigenous peoples of Amazonia, their cultures, land use patterns and effects on the landscape and biota. In: SIOLI, H. (Ed.). The Amazon. limnology and landscape ecology of a mighty tropical river and its basin. Dordrecht: Dr. W. Junk Publishers, 1984. p. 627-648.

MMA - Ministério do Meio Ambiente. Agenda 21 brasileira: resultado da consulta nacional/Comissão de Políticas de Desenvolvimento Sustentável e da Agenda 21 Nacional. 2. ed. Brasília: Ministério do Meio Ambiente, 2004. 158 p.

PADOCH, C; AYRES, J. M.; PINEDO-VASQUEZ, M.; HENDERSON, A. Várzea: diversity, development, and conservation in Amazonia's whitewater floodplains. New York: The New York Botanical Garden Press. 1999. 407 p.

POFFENBERGER, M.; McGEAN, B.; RAVINDRANATH, N. H.; GADGIL, M. Diagnostic tools for supporting joint forest management systems. New Delhi: Joint Forest Management Support Program, 1992. $101 \mathrm{p}$.

PUERTA, P.; BODMER, R; ARÉVALO, F. Manual para la elaboración de planes de manejo de fauna silvestre en la cuenca del Samiria, Reserva Nacional Pacaya-Samiria, Perú. Kent: Durrell Institute of Conservation and Ecology, 2004. 28 p.

SEN, S.; NIELSEN, J. R. Fisheries co-management: comparative analysis. Marine Policy, Amsterdam, v. 20, p. 405-418, 1996.

VERÍSSIMO, J. A pesca na Amazônia. Rio de Janeiro: Livraria Alves, $1895.137 \mathrm{p}$. 